\title{
Ünlüler ile ilgili kuramlar çerçevesinde Türkçedeki ünlüler
}

\section{Gönül ERDEM NAS'}

APA: Erdem Nas, G. (2020). Ünlüler ile ilgili kuramlar çerçevesinde Türkçedeki ünlüler. RumeliDE Dil ve Edebiyat Araştirmaları Dergisi, (Ö7), 237-252. DOI: 10.2900o/rumelide.813412.

\section{Öz}

Dilbilim; ses, yapı ve anlam üçgeni içerisinde dilin bütünlerini ayrıntılarıyla incelemektedir. İncelemenin hareket noktası ses bölümüdür. Seslerin oluşturduğu anlamlı bütünler, yapısal birliktelikler oluşturarak üst yapıları ve anlamları meydana getirmektedir. Ses yapıları, belli kuram ve çalışmalar ışı̆̆ında dilin hareketli yapısına eş bir biçimde bazen art zamanlı bazen de eş zamanlı olarak ele alınır. Çalışma, ses yapılarını ünlü uzamları esasında geçmişten günümüze belirlenen kuramlar çerçevesinde inceleme amacı taşımaktadır. Geçmişten günümüze bu konudaki ilk bu konudaki tespitlerin işitsel sesbilgisi ışı̆̆ında gerçekleştiği bilinirken günümüzde ise teknoloji araçlarının sunduğu olanaklarla eklemleme ve işitsel çözümleme ile daha ayrıntılı sonuçlar elde edilebilmektedir. Ses ve ses yapıları dilbilim içerisinde "sesbilgisi (fonetik) ve sesbilim (fonoloji)" başlıkları altında incelenir. Dünya üzerinde konuşulan tüm dillerde ünlüler bulunur. Her bir dil sistemi içerisinde bu ünlülerin dağılımı ve sayısı birbirinden farklılıklar gösterir. Bunun ayırdına varan dilbilimciler özelde de sesbilimciler dünya dillerindeki ünlü yapılarını hem o dil içinde hem de diğer dillerle ilişkileri bakımından ele almıştır. Çıkan sonuçlar, bazı kuramların gelişmesini sağlayarak dil bütününün en temel verisi olan ünlüler için bizlere fikirler vermiştir. Çalışmada bu kuramların en bilinenleri ele alınarak Türkçedeki ünlü uzamı bu kuramlar çerçevesinde değerlendirilmiştir. Bununla birlikte Türkçenin ünlü nitelikleri kadın ve erkek konuşurlara ait ses laboratuvarında alınan kayıtlar ışı̆̆ında formant değerleriyle çalışmada sunulmuştur. Böylelikle Türkçenin ünlü uzamının nitelik bakımından görünümü çalışmayla vurgulanmaktadır.

Anahtar kelimeler: Sesbilim, sesbilgisi, ünlüler, ünlü kuramları

\section{Vowels in Turkish within the framework of theories related to vowels}

\begin{abstract}
Linguistics; examines the sound, structure, meaning and entirety of language within a comprehensive triangle. The starting point of the examination is the part of sound. The meaningful parts formed by the sounds constitute the superstructures and meanings by forming structural unities. Sound structures are discussed in the light of certain theories and studies in line with the dynamic structure of the language, in some cases concurrently and in some cases simultaneously. The study aims to examine the sound structures within the framework of the theories determined from the past to the present, based on vowel space. While it is known that the first determinations on this subject have been realized in the light of auditory phonetics from the past to the present, more detailed results can be obtained by articulation and auditory analysis with the possibilities offered by technological tools. Sound and sound structures are examined under the title of phonetics and phonology in linguistics. There are vowels in all languages spoken around the world.
\end{abstract}

$1 \quad$ Dr. Öğr. Üyesi, Bartın Üniversitesi, Edebiyat Fakültesi, Çağdaş Türk Lehçeleri ve Edebiyatları Bölümü (Bartın, Türkiye), gonulerdem2002@yahoo.com, ORCID ID: 0000-0001-8100-3884 [Makale kayıt tarihi: 15.09.2020-kabul tarihi: 20.10.2020; DOI: 10.29000/rumelide. 813412. 
Within each linguistic system, the distribution and number of these vowels differ from each other. Linguists and phonologists in particular, who are aware of this, have discussed the vowel structures in world languages both within and in terms of their relations with other languages. The results by providing the development of some theories brought out some new ideas about the vowels, which are the most basic data of a whole language. In this study, the most well-known of these theories are considered and the vowel space in Turkish has been evaluated within the framework of these theories. In addition, the qualities of vowles in Turkish are presented in the study with formant values in the light of the recordings taken in a sound laboratory of male and female speakers. Thus, the view of the vowel space of Turkish in terms of quality is emphasized by the study.

Keywords: Phonology, phonetics, vowels, theories

\section{Giriş}

Dilbilim, dili oluşturan tüm parça ve parça dışı unsurları inceler. Üç başlık altında ve bu başlıkların da altında birçok bölümde bu incelemeyi yaparken ana inceleme konusu art ve eş zamanlı dildir. Bu üç başlık ses, yapı ve anlam üzerine şekillenmekte ve bunlara bağlı olarak ses için sesbilim, sesbilgisi; yapı için biçimbilgisi, sözdizim ve anlam için ise anlambilim, edimbilim çalışmalarını kapsamaktadır.

Bu çalışmada ele alınacak konular, dilbilimin ses ile ilgili bölümüyle ilgilidir. Dünya üzerinde konuşulan ve tespit edilen tüm dillerde ünlüler bulunur. Bu ünlülerin kendi uzamlarındaki sayı ve özellikleri farklılık gösterir. Ünlülerin sayı ve nitelikleri diller arasındaki ilişkileri benzer ya da farklı yönleriyle (tipolojik) incelenmesini sağlar. Dilbilimin ses kısmını inceleyen sesbilgisi ve sesbilim dalları içerisinde ünlüler temel inceleme konusudur. Çünkü ünlülerin tanımlanması hecelerin de niteliğini sunmasını sağlamaktadır. Birçok dilde ünlüler aynı zamanda heceleri belirtmektedir. Bunun istisnaları da bulunabilir. Hece yapısında hiç ünlü bulunmayan fakat sesletimi sırasında kayan ünlü özelliği gösteren hece yapıları da bulunmaktadır.

Çalışmada ünlüler, dil sistemindeki yerleri ve dillere göre sayılarının niteliksel tanımları öncül kuramlar çerçevesinde incelenmiştir. Ünlüler herhangi bir engele takılmaksızın ağız içerisinde küçük bir bölgede oluşmaktadır. Bu temel bilgi ilk dönem dilbilimciler tarafından da fark edilmiştir. Bu bölgeye "sürekli ünlü bölgesi" diyerek daha sonra ünlü oluşumunda dilin üstlendiği rolle birlikte bu tanımı genişletmişlerdir. En eski dil kuramcıları -ki bu 14 yy geride 7. yüzyıla kadar uzanmaktadırünlüleri çene açıklığı esasında damaksıl(ağız), dudak-art damaksıl (dudak) ve boğazsıl-yutaksıl (boğaz) ünlüleri olarak niteleyerek daha önceki ses üretim organı olarak tek gösterilen ağzı, ünlü üretiminde daha çok ayrıntılı incelemişlerdir.

19. yüzyıla gelindiğinde Alexander M. Bell (1867), işitme engelli çocuklara konuşmayı öğrettiği sırada İngilizcede bazı sözcüklerin sesletiminin farklılığını ve buna yönelik sesletim önerilerini geliştirmek üzere daha önce belirlenmiş ünlüler dışında "karışık" ünlülerin olduğundan bahsetmiştir. Karışık ünlüleri dilin hareketleri üzerinden inceler. Dilin ağız boşluğundaki daraltma hareketi üzerinden yüksek-alçak ve ön-arka olmak üzere ünlülerin üretimi üzerindeki etkilerini incelemiştir. Daha önceki ünlü tanımlarında bu tür bir sınıflandırma bulunmamaktaydı. Bell (1867) ses yolunu ve ünlü oluşumunu şu biçimde tanımlamıştır: 


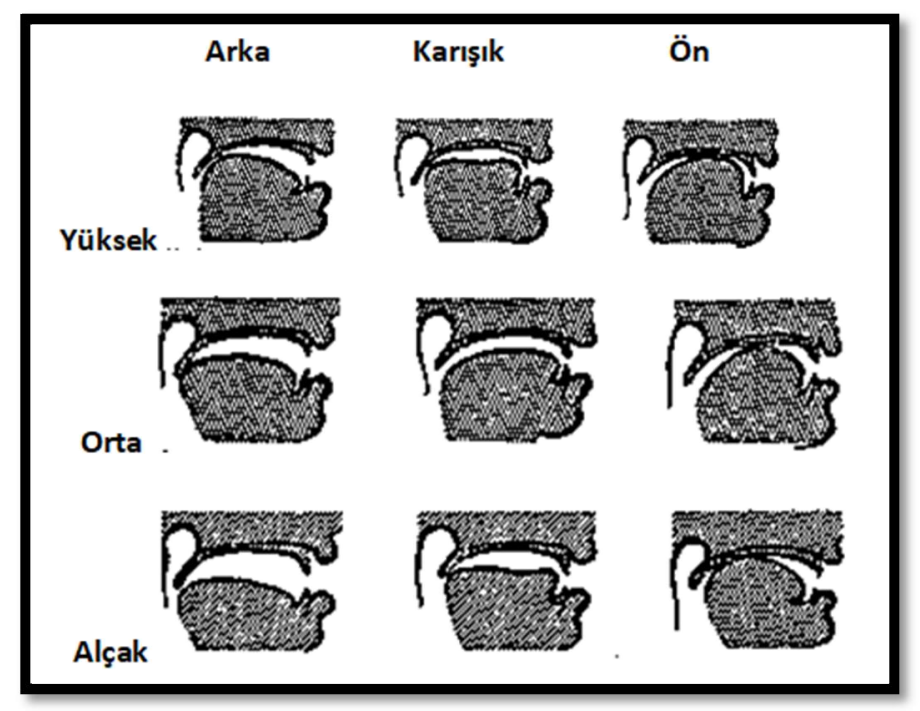

Şekil 1. Bell'e göre ünlü oluşum noktaları

\section{Kardinal (Ana) ünlü kuramı}

İngiliz sesbilimci Daniel Jones $(1956,1972)$ tarafindan ortaya atılan bu kuramda "Ünlüler, dil dizgesinin ahengidir ve ağız içinde temel referans noktalarında oluşurlar” görüşü bulunur. Ünlüler, ağzın nispeten küçük bir bölümünde üretilir. İlk çalışmalar bu üretimi iki temel nokta içerisinde değerlendirmiştir. Damak ve art damak olmak üzere damakta en önde boğumlananlar ele alınırken art damak içinse en arkada boğumlanan ünlüler sınıflara ayrılarak incelenmiştir. Bununla birlikte dilin ve dudakların işlevi ilerleyen çalışmalarla birlikte ele alınmıştır. Dil, ağız içinde ses üretim sürecinde önarka ve aşağı-yukarı olmak üzere devinim içindedir. Dudaklar da düz ve yuvarlak şekiller alarak bu üretim içerisinde yer alır. Dillerdeki ünlülerin şemalandırılması dilin devinimi esasıyla oluşur. Dilin devinimi sırasında her ünlü için bir nokta belirlenir ve bu noktalar dillerin ünlü uzamını oluşturur; bu bazen dörtgen bazen üçgen şeklinde olabilir. Bu şekiller dildeki ünlü köşelerini belirler. Dilin eğimi bu ünlü uzamlarının oluşumunda etkenlerden biridir. Dilin en yüksek noktasındaki konumu, ünlülerin noktalar halinde işaretlenip ünlü uzamının oluşturulmasında kullanılır. Bu sebeple ünlü sınıflandırmasında dilin en yüksek noktasının belirlenmesi çok önemlidir.

Ünlüler, üretimleri esnasında dilin yüksek-alçak ve ön-arka devinimlerinde bir dörtgen uzamı içerisinde temel ünlüler esasında yerleştirilmiştir. O dönemde Jones'un ünlüleri sesletirken kendi ağız görüntülerini X ışınları yardımıyla belirlemiştir. X ışınlarıyla dilin devinimi belirlenemediğinden kuram, ünlüleri varsayım üzerine dörtgende yerleştirmiştir. Bu kuramda iki ana ünlü bulunur [i] ve [a]. Sebebi de [i] ünlüsünün dilin en yüksek ve ağzın mümkün olan en ön kısmında üretilmesi iken [a] ünlüsünün ise dilin en alçak ve ağzın mümkün olan en arka kısmında üretilmesidir. Kalan ünlüler bu iki ana ünlü arasında eşit biçimde dilin ön-arka ve yüksek-alçak konumları gözetilerek yerleştirilmiştir. $\mathrm{Bu}$ ana iki ünlüye ek olarak [u] ünlüsü de yine arka ve dilin yüksek olduğu şeklinde üretilmesinin yanı sıra yuvarlak olma özelliğiyle üçüncü ana ünlü özelliği taşımaktadır. Sesbilimciler farklı dillerdeki ünlüleri tanımlamak ve dilleri karşılaştırmak için "Kardinal Ünlü” adını verdikleri temel kaynak ünlüleri kullanırlar. Bu ünlüler ünlü üretim bölümlerinin her bir ucunda üretilen dört ünlüden oluşur: [i], [a], [a] ve [u]. Bunlar, en köşelerde oluşurken diğer ünlüler bu ünlülerin arasındaki bölümlerde oluşur. Bu kaynak ünlülerden oluşan ünlü uzamı Uluslar arası Ses Alfabesi’ni (IPA) oluşturur. 
Bu kuramda ünlü uzamı iki şekilde incelenir birincil Kardinal Ünlüler ve ikincil Kardinal Ünlüler. Her ikisi de sekiz oluşum noktasında üretilen toplam on altı ünlüden oluşan bu sistemde Jones kendi sesiyle kayda aldığı ünlüleri numaralarıyla dörtgende göstermiştir. Birincil ünlüler numara sıralarına göre şunlardır: 1 [i], $2[\mathrm{e}], 3[\varepsilon], 4[\mathrm{a}], 5[\mathrm{a}], 6[0], 7[\mathrm{o}]$, ve $8[\mathrm{u}]$. Birincil ünlüler ile birlikte dudakların aldığı şekil de işin içine katılarak oluşturulan ikincil ünlüler bulunur. Aşağıda oluşum noktalarına göre ünlüler bulunmaktadır (Jones, 1956:131-134).

\begin{tabular}{|l|l|l|l|l|}
\hline \multicolumn{2}{|l|}{ Birincil Kardinal Ünlüler } & \multicolumn{2}{l|}{ İkincil Kardinal Ünlüler } \\
\hline & Ön & Arka & Ön & Arka \\
\hline Kapalı & i & u & y & u \\
\hline Yarı-kapalı & e & o & $\varnothing$ & r \\
\hline Yarı-açık & $\varepsilon$ & $o$ & œ & $\Lambda$ \\
\hline Açık & a & a & E & v \\
\hline
\end{tabular}

Tablo 1. Birincil ve İkincil Kardinal Ünlüler

Jones’un öğrencileri olan Ladefoged (1967), Peterson ve Barney (1952) Kardinal ünlüleri daha sonra nicelik bakımından da incelemişlerdir. Amerikan İngilizcesindeki ünlüleri kapsayan ve Mel ölçeğinde hesaplanan ünlülerin Jones tarafından belirlenen ölçütlere uyup uymadığı incelenmiştir. Buna göre alınan kayıtlarda ünlüler F1 ve F2 değerleriyle ünlü dörtgeniyle büyük ölçüde örtüşmektedir. Bir dörtgen vardı ve bu bazı sapmalar dışında işlevseldi.

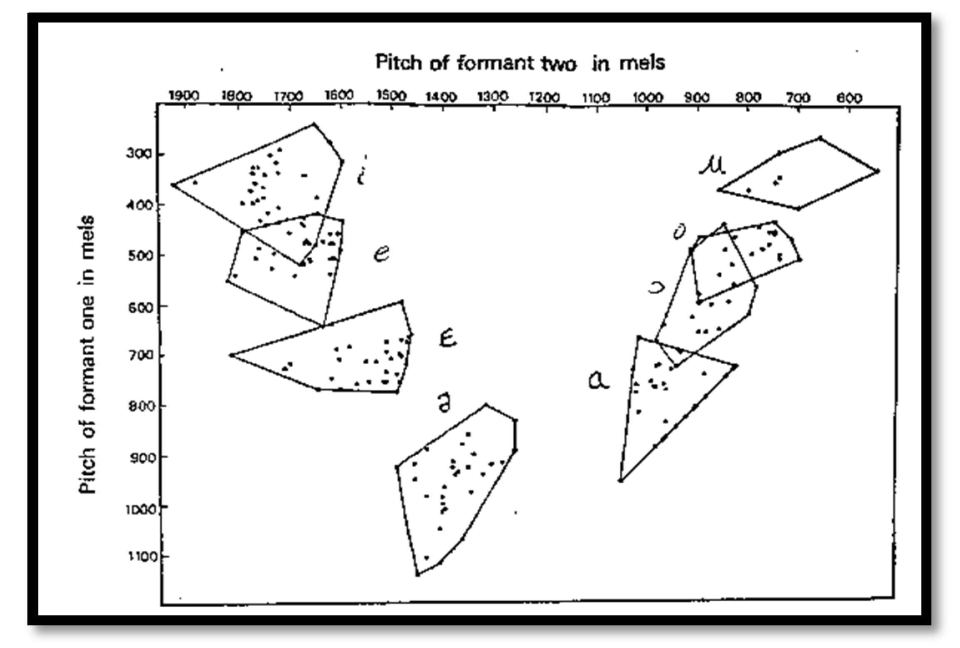

Şekil 2. Ladefoged’in Mel ölçeğine göre ünlü ölçümü 


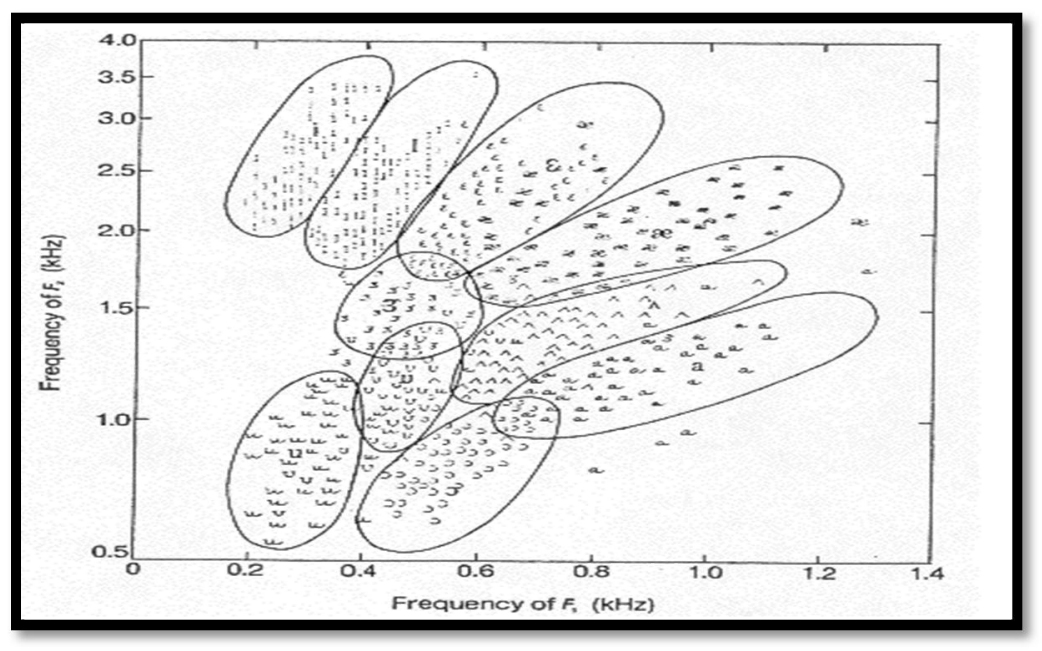

Şekil 3. Peterson ve Barney’in ünlü formant ölçümü

Kardinal Ünlü Kuramı, daha önceki ünlü tanımlarını daha bilimsel ve ölçülebilir bir noktaya taşıması bakımından öncül ve önemlidir. Bununla birlikte dilin devinimini ve dudakların durumunu kapsamadığı için sınırlılıklara sahiptir. Belirlenen birincil seslerin sayısının neye göre belirlendiği açık olmaması ve burada kullanılan ünlü dörtgeninin köşelerini oluşturan ünlülerin hiçbir dile ait olmaması, belirlenen bu sayının da rastlantısal olduğunu göstermektedir. Bu dörtgenin önemi, dil içinde ve diller arasında bir ünlü tanımı yapmada sesbilimciler tarafından kullanılıyor olmasıdır.

Bir dildeki ünlü sayımcasını (envanterini) belirlemek ve Kardinal ünlülerle olan ilişkisini çözmek, ünlülere verilecek sembollerin belirlenmesi bakımından önemlidir. Konuşma sesleri içinde ünlünün Kardinal ünlüye olan uzaklığı +/- değerlerle belirlenmektedir. Dörtgen içinde yeri bu sistemle belirlenen ünlünün yazıdaki transkripsiyonu daha kolay yapılabilmektedir. Bu kuram, Türkçe gibi ikili veya üçlü ünlü sistemine (diftong, triftong) sahip olmayan dillerde ünlü uzamını belirlemede kolaylıkla kullanılabilir. Kuramın sesbirimden öte altsesbirimlerin (özellikle lehçe ve ağız çalışmalarında) tespitinde ve dörtgen içindeki konumunda ise F1 ve F2 değerlerinin belirleyici olduğu bir gerçektir. Örnekle açıklanırsa bir yöreden derlenen ve Standart Türkçe yapısından farklı olan "gordüm” sözcügü̈ için [o] sesi tam anlamıyla [o] veya [ö] seslerini temsil etmemektedir. Dörtgen içindeki yerinde ise [o], [o]'dan biraz daha gelişmiş anlamı taşır. Böylelikle bu sesi tanımlayacak sembolün oluşması için basit bir yol izlenmiş olur. İşitilen seslere dörtgendeki kardinal ünlülere göre verilen +/- değerlerle söz konusu seslerin çevre sesleri de gözetilerek yapılacak çözümlemeyle sembolleri bulunabilir.

\section{Peterson ve Barney'in ünlüler ile ilgili çalışmaları}

İngiliz Dil Okulu'ndan Peterson ve Barney (1952) öncülleri Jones’un çalışmalarını takip eden ve İngilizcedeki ünlülerin üretimini inceledikleri çalışmalar yapmışlardır. Örneklem alanı olarak Amerikan İngilizcesini seçen araştırmacılar "h...d" (had, hid,head vb.) ile oluşturulmuş birbirine yakın 10 sözcüğü 33 erkek, 28 kadın ve 10 çocuğa sesleterek ölçümlerde bulunmuşlardır. Ölçüm için alınan ses kayıtları Fo, F1, F2 ve F3 değerleri bakımından incelenmiştir. Deneyin bu kısmı sesi üretenlerle ilgiliyken diğer kısmında ise işitsel sesbilgisi bakımından ölçümler yapmak amacıyla alınan bu ses kayıtları 70 dinleyiciye dinletilerek sözcüklerde geçen ünlülerin algllanma düzeyleri de tespit edilmek istenmiştir. Toplam 71 konuşmacıdan alınan ses kayıtlarına göre ünlü frekans değerlerini şu şekilde belirlemişlerdir: 


\begin{tabular}{|c|c|c|c|c|c|c|c|c|c|c|c|}
\hline $\begin{array}{l}\text { Pupdamental freguencies } \\
\text { (థpa) }\end{array}$ & $\underset{C}{W}$ & $\begin{array}{l}i \\
\text { iss } \\
235 \\
m 2\end{array}$ & $\begin{array}{l}135 \\
132 \\
269\end{array}$ & $\begin{array}{l}{ }_{130} \\
223 \\
200\end{array}$ & $\begin{array}{l}x \\
127 \\
210 \\
251\end{array}$ & $\begin{array}{l}\stackrel{2}{124} \\
212 \\
255\end{array}$ & $\begin{array}{l}20 \\
120 \\
216\end{array}$ & $\begin{array}{l}\text { 137 } \\
232 \\
236\end{array}$ & 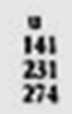 & $\begin{array}{l}\hat{130} \\
221\end{array}$ & $\begin{array}{l}3 \\
13 \\
218 \\
261\end{array}$ \\
\hline Formunt trequencies (cps) & & & & & & & & & & & \\
\hline $\boldsymbol{F}_{\mathbf{1}}$ & $\stackrel{M}{W}$ & $\begin{array}{l}270 \\
310 \\
370\end{array}$ & $\begin{array}{l}320 \\
430 \\
50\end{array}$ & $\begin{array}{l}500 \\
610 \\
600\end{array}$ & $\begin{array}{r}600 \\
800 \\
1010\end{array}$ & $\begin{array}{r}730 \\
850 \\
1030\end{array}$ & $\begin{array}{l}590 \\
990 \\
6000\end{array}$ & $\begin{array}{l}400 \\
\$ 00 \\
500\end{array}$ & $\begin{array}{l}300 \\
370 \\
40\end{array}$ & $\begin{array}{l}610 \\
260 \\
850\end{array}$ & $\begin{array}{l}500 \\
500 \\
560\end{array}$ \\
\hline$F_{\mathbf{i}}$ & $\begin{array}{l}\boldsymbol{H} \\
\boldsymbol{C} \\
\boldsymbol{C}\end{array}$ & $\begin{array}{l}2000 \\
2 m 00 \\
3200\end{array}$ & $\begin{array}{l}1990 \\
2480 \\
2730\end{array}$ & $\begin{array}{l}1840 \\
2310 \\
2610\end{array}$ & $\begin{array}{l}1720 \\
2050 \\
2320\end{array}$ & $\begin{array}{l}1000 \\
1220 \\
1370\end{array}$ & $\begin{array}{r}840 \\
920 \\
1060\end{array}$ & $\begin{array}{l}1000 \\
1160 \\
1+10\end{array}$ & $\begin{array}{r}870 \\
950 \\
1170\end{array}$ & $\begin{array}{l}1190 \\
1 \neq 00 \\
1900\end{array}$ & $\begin{array}{l}1350 \\
16 \% 0 \\
1800\end{array}$ \\
\hline$F_{3}$ & $\underset{C H}{\mathbb{W}}$ & $\begin{array}{l}3010 \\
3310 \\
3730\end{array}$ & $\begin{array}{l}2550 \\
3070 \\
3600\end{array}$ & $\begin{array}{l}2480 \\
2990 \\
35>0\end{array}$ & $\begin{array}{l}2410 \\
2 \times 50 \\
3320\end{array}$ & $\begin{array}{l}2400 \\
2310 \\
3170\end{array}$ & $\begin{array}{l}2410 \\
210 \\
3180\end{array}$ & $\begin{array}{l}200 \\
2600 \\
3310\end{array}$ & $\begin{array}{l}22 \% 0 \\
2670 \\
3200\end{array}$ & $\begin{array}{l}2390 \\
2780 \\
3360\end{array}$ & $\begin{array}{l}1600 \\
1960 \\
2160\end{array}$ \\
\hline Formant amplitodes (db) & $\begin{array}{l}L_{1} \\
L_{2} \\
L_{3}\end{array}$ & $\begin{array}{l}-4 \\
-24 \\
-28\end{array}$ & $\begin{array}{r}-3 \\
-23 \\
-27\end{array}$ & $\begin{array}{l}-2 \\
-17 \\
-24\end{array}$ & $\begin{array}{l}-1 \\
-12 \\
-22\end{array}$ & $\begin{array}{r}-1 \\
-5 \\
-28\end{array}$ & $\begin{array}{r}0 \\
-7 \\
-34\end{array}$ & $\begin{array}{r}-1 \\
-12 \\
-34\end{array}$ & $\begin{array}{r}-3 \\
-19 \\
-43\end{array}$ & $\begin{array}{l}-1 \\
-10 \\
-27\end{array}$ & $\begin{array}{r}-5 \\
-15 \\
-20\end{array}$ \\
\hline
\end{tabular}

Tablo 2. Peterson ve Barney’in ölçümüne göre ünlü formant değerleri

Yukarıdaki tabloda M (erkek), W (kadın) ve Ch (çocuk) olmak üzere konuşmacılara ait formant değerleri bulunmaktadır. Buna göre Jones'un belirlediği Kardinal Ünlü Sistemi’ndeki gibi ünlülerin belirlenmesi tek ve durağan değildir. Akustik bakımdan oldukça fazla çeşitlilik ve farklılık bulunmaktadır. Bununla birlikte dinleyicilerin sözcükleri algılaması ve sözcükler içerisinde hangi ünlüleri karıştırdıkları incelenerek tablolaştırılmıştır:

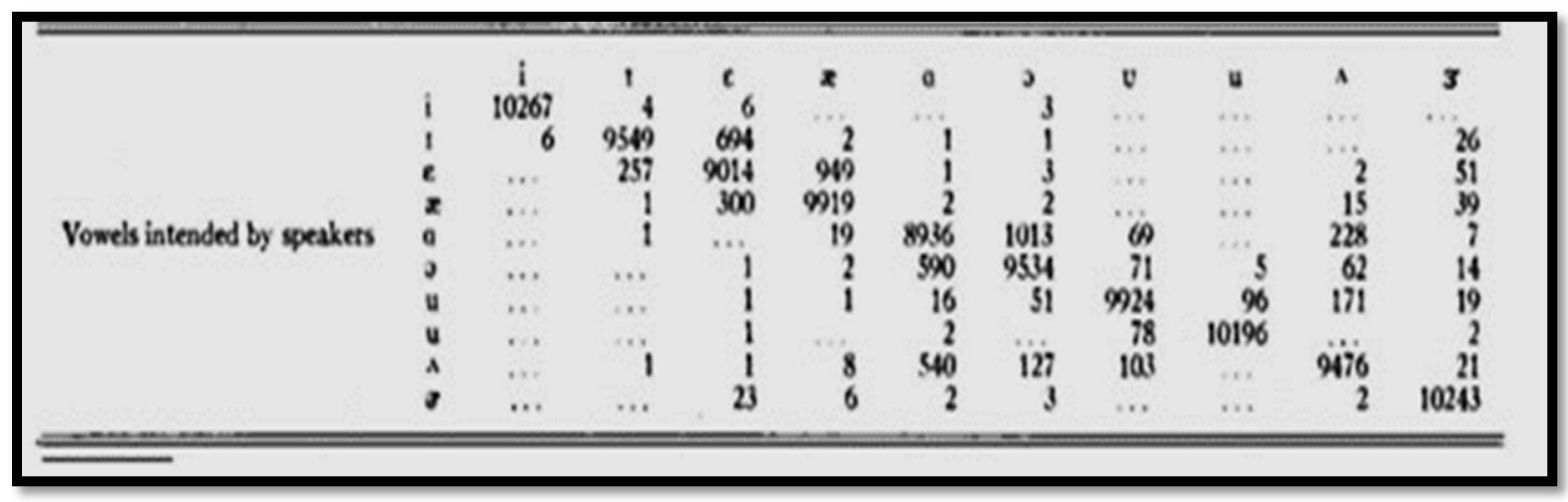

Tablo 3. Dinleyicilerin uyaran sözcüklere verdiği tepkiler

Birbirine sesletim bakımından benzeyen 10 sözcük içerisinde en çok "hod" "hawed" sözcügü ile karıştırılırken, en az "hid" "hud" olarak algılanmıştır. Bununla birlikte dinleyicilerin en doğru ayırt ettikleri sözcükler "heed”, “who'd” ve "herd” iken en az "hod” ve "head” sözcüklerini doğru ayırt etmişlerdir. Buna sebep olan etken ise ünlülerin çevresindeki komşu seslerin sesletime olan etkisidir.

Türkçede bu çalışma tek heceli sözcüklere uygulandığında formant değerlerinin farklılığı bu çalışmadaki gibi olacağından bu yönüyle bu çalışmadan ayrılır. Türkçede ikili ve daha çok ünlülü bir hece yapısının bulunmayışı, aynı zamanda tek heceli yapılarda uzun ünlünün bulunmayışı bu tür bir çalışmanın yapılması özellikle dinleyici algısı bakımından yüksek farklılıkların çıkmasına engeldir. Bu tür bir çalışma Türkçede yalnızca benzer sesler içerisinde ünlülerin nasıl üretildiğine yanıt aramak için yapılabilir. Dinleyiciler için İngilizcedekine benzer bir algı farklılığına sebep olacak tekli hece yapısı Türkçe için bulunmaz. 


\section{Nicelik (Quantal) kuramı}

Nicelik Kuramı, Stevens (1972,1989) tarafından akustik olarak konuşma seslerinin üretiminin fizyolojik verilerle açıklamak için ortaya atılmıştır. Yani sesbilimsel (fonolojik) bir soruna sesbilgisel (fonetik) bir yanıt arama amacı taşımaktadır. Sayısız sesbirim seçeneği içerisinde dillerin neden bazı sesbirimleri daha fazla seçtiğine açıklık kazandırmak için deneysel çalışmalarda bulunan Stevens dillerin büyük bir kısmında [a, i, u] ünlülerinin ortak olduğu görüşünden hareketle bu ünlülerin tercih edilme sebebinin onların üretimindeki kolaylıkları olduğu savını güçlendirecek sesbilgisel veriler sunmuştur. Bu seslerin Jones'tan bu yana biliniyor olması sesbilimsel bir veriyken bu ünlülerin dünyada birçok dil tarafından neden tercih ediliyor oluşuna sesbilgisel bir yanıt kuramda ele alınmıştır. Ünlülerin seçiminde üretime dayalı kolaylığın sezgisel olma durumu bu kuramın sağladığı verilerle daha bilimsel düzleme yerleşmiştir. Buna göre üretimi daha kolay olan sesbirimler diller içinde daha yaygınken üretimi zor olanlar daha az tercih edilmektedir.

Bu kurama göre ses yolundaki en küçük değişiklik, üretimin çıktısı olan sesin akustik özelliğini etkiler. Bu etki, akustik ve eklemlenme içerisinde sürekli bir doğrusallıkta gerçekleşmez (K. N. Stevens, 1989:4):

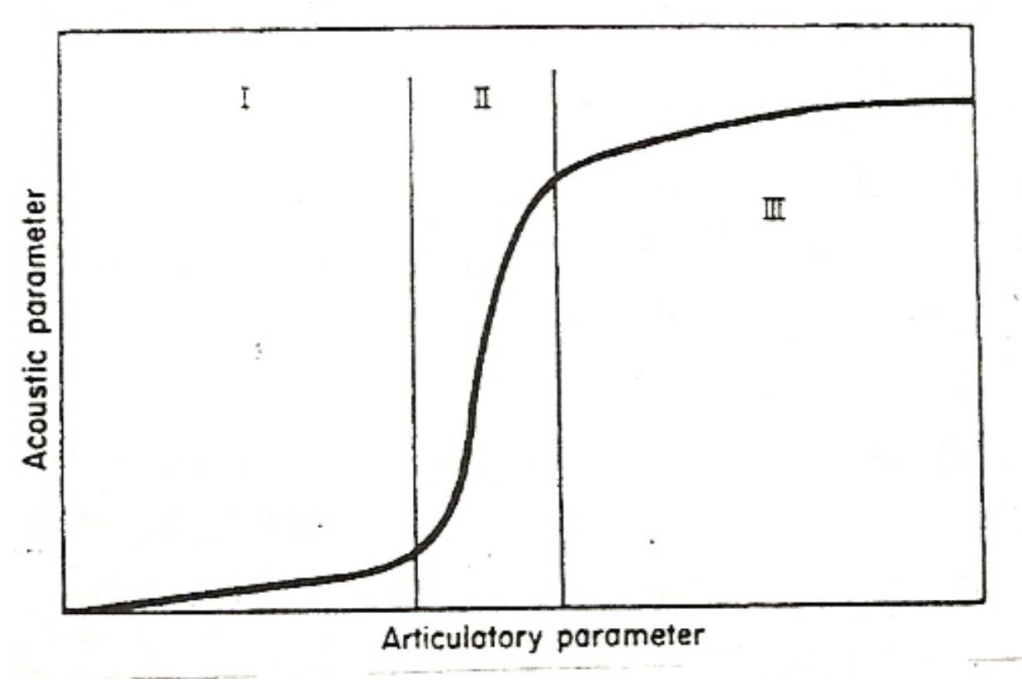

Şekil 4. Stevens’a göre akustik-eklemleyici özellikler arasındaki ilişki

Yukarıdaki şekilde I ve III. Bölgeler arsasında hem akustik hem de eklemleme farklılıkları bulunur. Bu değişikliğin sebebi kurama göre eklemlemedeki değişikliklerin ses çıtısına olan etkisinden değil, her iki bölge arasındaki dilsel karşıtlıklardan dolayıdır. Bu bölgelere Kuantal (nicelik) bölgeleri denmektedir ve bu bölgeler karşıt sesleri içermektedir. Bir sesin üretiminde hassas eklemlenmeye ihtiyaç yoktur. Eklemlemede oluşan bir eğim bu sebeple çıktının algllanabilirliğini doğrudan etkilemeyebilir. Çıktı olarak sesin üretilmesinde ise sürekli bir eklemlemeye ihtiyaç vardır. $\mathrm{Bu}$ eklemleme; gırtlaktaki daralma derecesi (ötümsüzler için açı, ünlüler için daha az açı, gırtlak sesleri için kapalı), ses yolundaki daralma derecesi (daralma sırası bakımından, ünlüler- kayan ünlülersürtünmeliler-patlamalılar) ve ünlülerin eklemlenme (daralma) yerleri bakımından incelenir.

Ünlülerde bu kuram, formant ölçümlerine dayalı çıkan sonuçlarla belirlenir. Formantların birbirine yarım oktavdan daha yakın olduğu ya da birleştiği durumlarda bu sesler tek formant olarak algılanır. 
Birçok ünlünün ayrımı bu yarım oktav eşiği üzerinde bulunur (Örn. "but" ve "bot" sözcüklerinde ünlülerin formantları birbirine yarım oktav kadar yakındır).

İki formantın birleştiği akustik kuantal bölgeler vardır. [a, i, u] temel ünlüleri için bunlar Stevens (1989) tarafından şu şekilde ölçülerek belirlenmiştir:

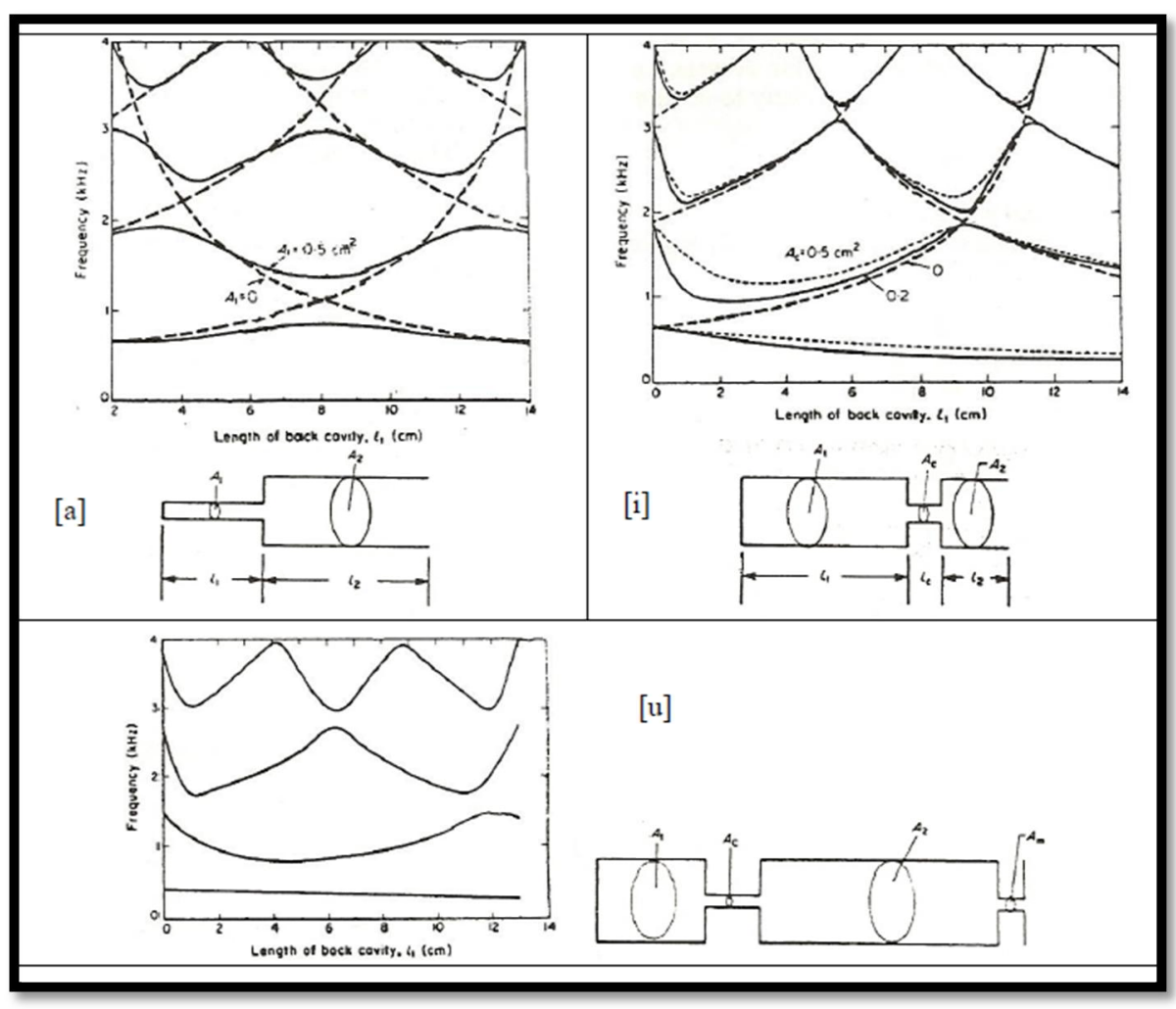

Şekil 5. Temel ünlülere ait Kuantal bölgeler

Şekilde [a] ünlüsünün F1 ve F2'nin çakışmasıyla oluştuğu görülmektedir. Bu sesin üretiminde ses yolundaki ön ve arka boşluklar eşit uzunluktadır. [i] ünlüsünde ise damakta oluşan daralma sonucu F2 ve F3 çakışmaktadır. [u], F2'nin genişleyerek F1'e yakınlaştı̆̆ bölgede üretilir. Üretimlerindeki bu kolaylık söz konusu üç ünlüyü diller arasında tercih edilir kılmakta, bu sebeple de kuantal (niceliksel) sesbirim olmalarını sağlamaktadır.

Dillerde ses üretiminde kolaylık sağlayan kuantal (nicelik) bölgeleri bulunur ve diller bu sesleri daha çok seçme eğilimindedir. Bu bölgelerde oluşturulan parçalı birimler diller arasında ortaklığı sağlayacakken bu bölgeler dışında kalan parçalı birimler bu ortaklığın dışında kalacaktır.

Jones'un kuramından bu kurama dek ortak olan konu diller arasında bazı seslerin üretim kolaylığı bakımından ortaklığı ve farklılığıdır. Bu kuramda da Jones'un kuramına benzer geliştirilebilir yönler bulunur. Bununla birlikte diller arasındaki özellikle akustik benzerlikler kuramda belirtilenden daha fazladır. Karşıtlıklar arasındaki mesafe, bu kuramda değinilmeyen konular içerisindedir. Bir sesbirimin oluşumunda birden fazla eklemlenme durumu da kuram içerisinde değerlendirilmez. Eklemlenmedeki eğilimin etkisi ayrıntılı ele alınmamaktadır. En önemli katkısı ise sezgisel olarak bilinen bazı sesbirimlerin tercih sebeplerinin ölçüme dayalı ispatıdır. 
Stevens'ın kuramı daha sonra Keyser ve Kawasaki (1986) ile yaptığı çalışmalarla genişletilerek sesbirimlerin üretimindeki çoklu eklemlemeler de ele alınmıştır. Hem eklemlenmedeki çeşitlilik hem de sesin şiddeti sesbirimler üzerindeki çalışmalara dâhil edilmiştir. Örnek olarak birden fazla ayırt ediciliğe sahip "sen" ve "ten gibi iki sözcükte eklemlenme yeri bakımında (biri diş diğeri diş yuvası) ve sesin şiddeti bakımından farklılıkları -ünsüzler için- da incelenmiştir. Dillerdeki sesbirimlerin ayırt edici özelliklerinin güçlendirilmesi ve daha çok öne çıkarılması gerekliliğini savunmuşlardır (Örn. "tel" ve "del" sözcüklerinde ötümlülük dışında sesletim ve soluklanma farkı belirgindir. /t/ sesbiriminin sözcükte sesletiminde araya kısa bir /h/ gibi bir hava kabarcığı girerken bu durum /d/'nin sesletimi sırasında oluşmaz, bu da sesbirimler içindeki bu küçük ayrımların bile önemini göstermektedir).

\section{Uyarlanabilir dağılım kuramı (Theory of adaptive dispersion)}

Ünlüler, aralarındaki işitsel farklılıkları en yüksek düzeye çıkaracak biçimde sesbilgisel uzamda dağılım göstermektedir. Liljencrantz ve Lindblom (1972)'un geliştirdikleri bu Kuram da tam olarak bunu savunmaktadır. Ünlülerin işitsel farklılıklarının çok belirgin olması onları dinleyiciler tarafından daha doğru algılanabilir kılmaktadır düşüncesi kuramın hareket noktasıdır. Bu sebeple ünlü uzamındaki karşıtlıkları, geliştirdikleri formüllerle formant değerleri bakımından ölçmüşlerdir. Ayrıntılı ölçümlerle hedefledikleri, ünlülerin birbirleriyle olan farklılıkların çokluğunu gösterebilmekti. Ünlüler, bulundukları dillerdeki ünlü uzamlarında kenarlara yayılma eğilimindedir. Diğer kuramlara göre UDK dillerde normalde bulunandan daha çok ünlü ve ünlü karşıtllğı düşüncesini destekler. Diğer kuramlarda belirtilen [a, i, u] ünlülerinin seçimine farklı bir tanım sunar. Bu ünlüler akustik olarak oldukça farklıdır ve bu sebeple de dinleyiciler tarafından karşılaştırması yapılamaz. Bir ünlü uzamındaki ünlüler, bu uzamda eşit dağılım eğilimindedir. Yaygın seçimli ünlüler ünlü uzamlarındaki boşluklara rağmen nispeten daima eşit dağılımdadır (L ve L, 1972):

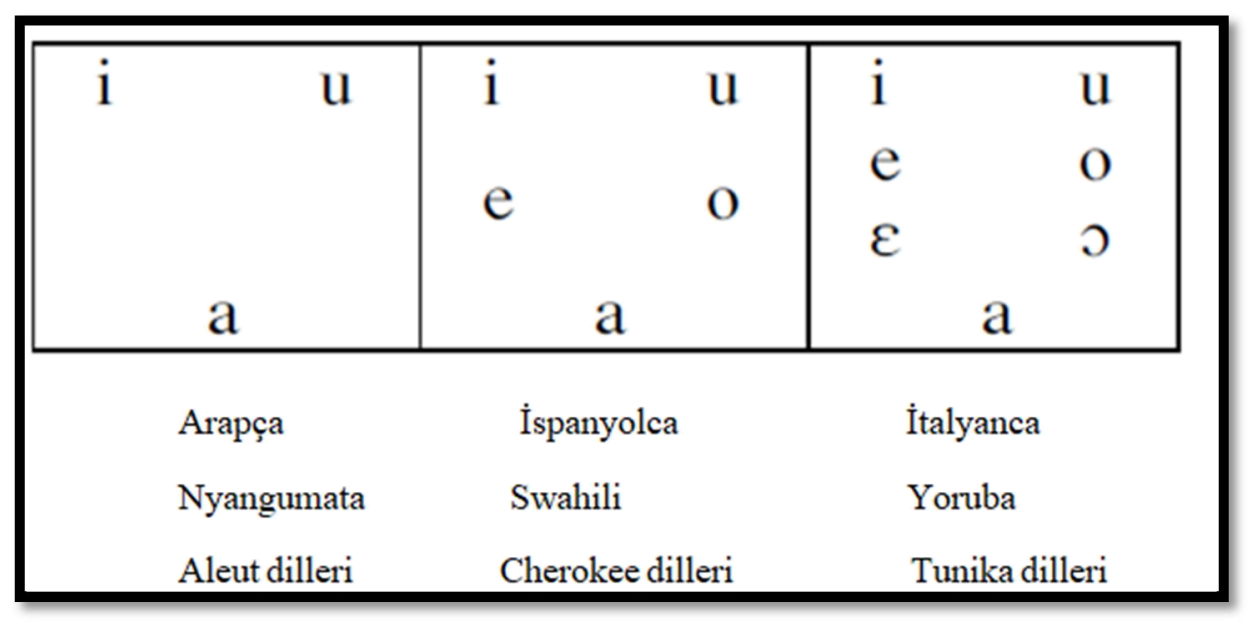

Şekil 6. Ünlü dağlımları ve bunları kullanan dillere örnekler

\begin{tabular}{|c|c|c|c|c|c|}
\hline i & i & $\begin{array}{l}\text { uI } \\
r\end{array}$ & $\begin{array}{l}\text { I } \\
\text { I }\end{array}$ & $\begin{array}{l}\mathrm{u} \\
\mathrm{u}\end{array}$ & $\begin{array}{lllll}\mathrm{i} & \mathrm{y} & \mathbf{1} & \mathrm{u} & \mathrm{u} \\
\mathrm{e} & \varnothing & \partial & \gamma & 0 \\
\varepsilon & \propto & \mathrm{e} & \Lambda & 0 \\
& \mathfrak{x} & \mathrm{a} & \mathrm{a} & \mathrm{p}\end{array}$ \\
\hline
\end{tabular}

Şekil 7. Diğer ünlülere göre diller arasında çok tercih edilmeyen ünlüler (Flemming: 1996, 1997, 2001, 2011).

Adres

Kurklareli Üniversitesi, Fen Edebiyat Fakültesi, Türk Dili ve Edebiyatı Bölümü, Kayalı Kampüsü-Kırklareli/TÜRKIYYE e-posta: editor@rumelide.com 
Algısal ayırt ediciliğin en yüksek düzeyde işlev olmasını sağlamak için belirli bir dildeki bazı seslerin "seçilmiş" olduğunu öne süren UDK, algısal karşıtlığın gerekliliğini de ünlü sayılarıyla açılar. Bu karşıtllı̆ı işitsel algıya dayalı $\mathrm{Hz}$ frekans ölçümü olan Mel ölçeği kullanarak ortaya çıkarır. Ayırt ediciliği formant değerinde ölçmek için şöyle bir formül geliştirmişlerdir:

$$
r_{i j}=\sqrt{\left(x_{i}-x_{j}\right)^{2}+\left(y_{i}-y_{j}\right)^{2}}
$$

$\mathrm{Bu}$ formülle ünlüler arasındaki algısal ayırt edicilik hesaplanmaktadır. Formülde geçen $\mathrm{x}=$ ünlüye ait F1 değeri, $y=$ ünlüye ait F2 değerini, $x$ ve y altında belirtilen i ve $\mathrm{j}$ ise iki farklı ünlüyü ifade etmektedir. Bu formülle elde edecekleri sonuçlardaki amaç; frekans değerleri arasındaki aralığın F1 ve F2'ye etkisi ve F1- F2'nin ulaşabilecekleri en üst ve alt sınırları hesaplamaktır.

Formant yoğunluğuna bağlı ünlü dağılımlarında birçok dilde köşe ünlüler [a, i, u] olarak bulunmaktadır. Bu ünlülerden [u] bazen bulunmaz bunun sebebi $\mathrm{F} 1$ değerinin yüksekliğidir. F1 değeri yüksek olan sesbirimler daha yoğunken $[\mathrm{u}]$ ünlüsünde hem F1 hem de F2 düşüktür. Bu sebeple seçimliliği diğer iki sesbirime göre düşüktür. Diğer iki ünlü ise -neredeyse- üzerinde çalışllan tüm dillerde bulunmaktadır:

- $\quad[\mathrm{i}, \mathrm{a}, \mathrm{o}]$, Piraha, Axeninca Campa dillerinde

- $\quad[i, e, a, o]$, Navajo, Klamath dillerinde

- $\quad[i$, e, a, o,u ], Tokyo Japoncasinda

UDK'de iç üretimli ünlülerin 10 ve biraz üstü olduğu tahmin edilmektedir. Her ünlünün diğer ünlüye olan uzaklı̆̆ı ayırt ediciliğini güçlendiren özelliğidir. İç üretim ünlüler, köşe ünlülere göre birbirine yakın üretim noktalarında olduklarından ayırt edicilikleri düşük bu sebeple de hesaplamaları diğer ünlülere göre daha güçtür.

\begin{tabular}{|c|c|c|c|c|}
\hline $\mathrm{i} y$ & $\mathrm{u}$ & $\mathrm{i}$ & $\dot{\mathbf{t}}$ & $\mathrm{u}$ \\
\hline e $\phi$ & $\mathrm{O}$ & $\mathrm{e}$ & $\partial$ & $\mathrm{O}$ \\
\hline \multicolumn{2}{|c|}{$\mathrm{a}$} & & a & \\
\hline
\end{tabular}

Şekil 8. İç üretim ünlüleri

UDK’ye göre ölçümlerle belirlenen en uygun -varsayım- ünlü uzamları şu şekilde verilmiştir: 


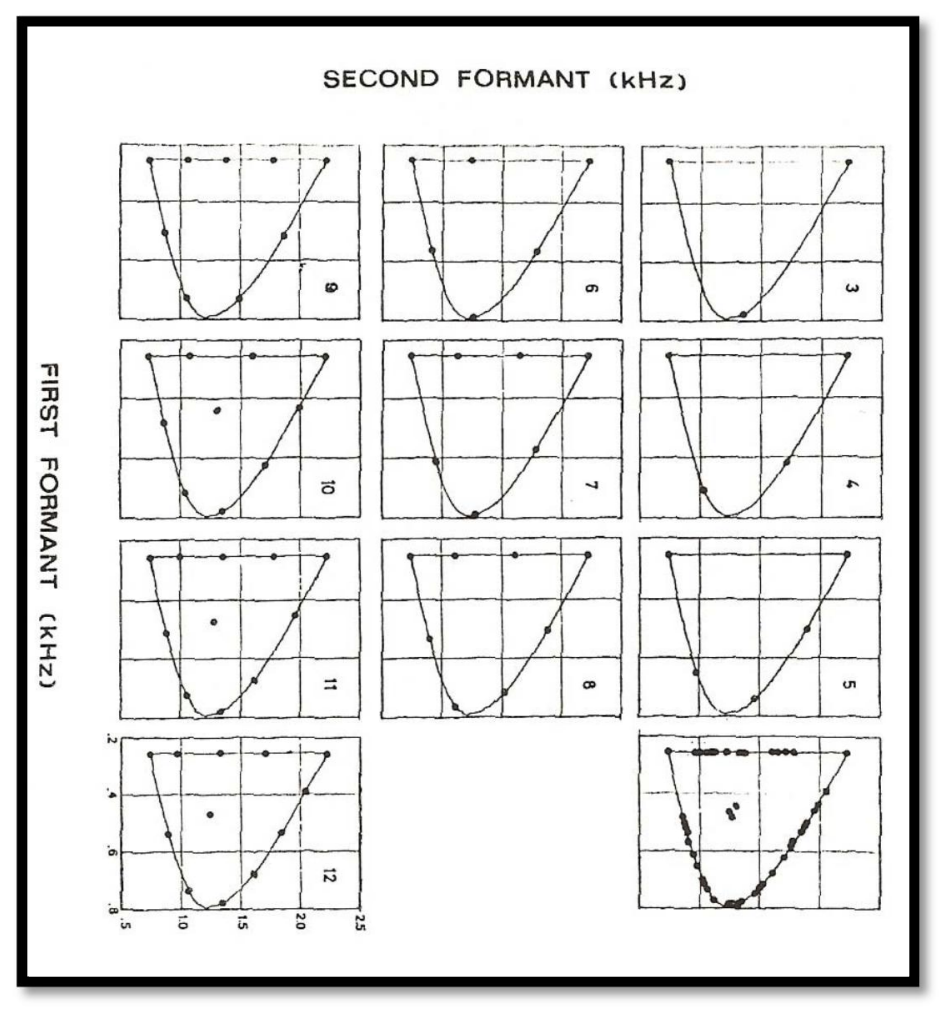

Şekil 9. UDK’de olası tüm ünlü uzam örüntüleri

UDK’ye göre bu ünlü uzamları içerisinde en doğru örüntü 3 ve 6 numaralı sistemlerdir. Daha geniş sayımcalar ise 7 ve sonrasındaki örüntülerdir. Ünlü sayımcası arttıkça algısal ayırt edici özelliklerin belirlenmesi de zorlaşmaktadır. Bu yönüyle UDK ünlü sistem yapılarını belirlemede önemli kuramlardan biridir.

UDK'nin ünlülerle ilgili ele almadığı konular da bulunmaktadır ki bunlar kuramın zayıf yönleridir. Dillerdeki ünlü sayımcalarının farklılığı üzerine bilgi içermez. Bununla birlikte aynı sayıda ünlüsü bulunan diller arasındaki farklı dağılımları da açılamaz. Diğer kuramlarda ele alınan eklemleme (artikülasyon) bu kuramda ele alınmaz.

İki kuram da (Quantal ve UDK) ortak bir görüşte birleşmektedir: sesbilgisi (fonetik) dilbilim içinde "sözlü" fizikî bir çıktıdır ve dili incelemekten çok konuşmaya odaklıdır. Bu kuramlar ise sözlü iletişim mekanizmalarının sonuçlarının üst dilbilimi nasıl etkilediğini açılkamaya çalışır.

Tüm kuramların ortak çıktısı seçimli ünlü kavramıdır. Ünlülerin diller arasında seçimli oluşunu ise akustik ve eklemleyici kolaylı̆̆a bağlamaktadırlar.

\section{Türkçedeki ünlüler}

Türkçe ünlü sayısı bakımından Dil Yapılarının Dünya Atlasında (WALS) büyük kategorisinde yer almaktadır. Yukarıdaki kuramlarda bahsi geçen köşe ünlüler olan [a, i, u] Türkçede bulunurken iç türetimli ünlü sayısı da fazla yapıdadır. 
Ünlü sınıflandırmasında belirlenen genel ölçütlere göre Türkçedeki ünlüler de çene açıklığı, dudak şekli ve dilin devinimine göre sınıflandırılmaktadır. Sesbilim bakımından 8 ünlüsü bulunan Türkçede sesbilgisi bakımından bu sayı artmaktadır. Sesbilim bakımından ünlüler:

- Çene açıklı̆̆ı bakımından (geniş: [a, e, o, ö], dar: [ı, i, u, ü]).

- Dudak biçimi bakımından (düz [a,e, , i], yuvarlak: [o, ö, u, ü])

- Dilin devinimi bakımından ( arka: [a,o,u], orta-arka: [1] ve ön: [e,i, ö, ü] olarak siniflandırilır.

Sesbilgisi bakımından ise -kısa- ünlüler Türkçede şu şekildedir (E. Erguvanlı, Taylan, 2015:17):

\begin{tabular}{|l|l|l|l|l|}
\hline \multicolumn{3}{|c|}{ ÖN } & \multicolumn{3}{c|}{ ARKA } \\
\hline & Düz & Yuvarlak & Düz & Yuvarlak \\
\hline Yüksek & i & y & u & ụ u \\
\hline Orta & e & $\varnothing$ & & o o \\
\hline Orta-alçak & e & & & \\
\hline Alçak & & & ạ a & \\
\hline
\end{tabular}

Tablo 4. Türkçedeki sesbilgisel ünlüler ve özellikleri

Bununla birlikte Türkçedeki sesbilimsel ünlülerin sayıca çok ve karışık gruplardan alınmış formant değerleri de bulunmamaktadır. Bu sebeple bu çalışma kapsamında ses laboratuvarında Shure KSM 32 model ses kayıt mikrofonu aracılı̆̆ıla bir kadın ve bir erkek konuşmacıya ait ses kayıtları ünlü sesletimi gözetilerek alınmıştır. Alınan bu ses kayıtlarının ses aralığı metronom ile eşit biçimde kayda geçirilmiştir. Elde edilen veriler PRAAT ses çözümleme programında formant değerleri bakımından incelenmiştir. Buna göre iki konuşucuya ait ünlü formant değerleri ve tablosu şu şekillerdedir:

\begin{tabular}{|c|c|c|c|c|}
\hline \multicolumn{3}{|c|}{ ERKEK } & \multicolumn{2}{|l|}{ KADIN } \\
\hline & F1(Hz) & F2 (Hz) & F1 (Hz) & F2 (Hz) \\
\hline /a/ & 810 & 988 & 906 & 1372 \\
\hline /e/ & 618 & 1989 & 646 & 2349 \\
\hline$/ 1 /$ & 350 & 1592 & 547 & 1402 \\
\hline /i/ & 275 & 2377 & 350 & 2640 \\
\hline /o/ & 624 & 750 & 647 & 975 \\
\hline /ö/ & 529 & 1480 & 640 & 1629 \\
\hline$/ \mathrm{u} /$ & 361 & 856 & 377 & 968 \\
\hline /ü/ & 226 & 2033 & 339 & 1904 \\
\hline
\end{tabular}

Tablo 5. Türkçedeki sesbilimsel ünlülerin kadın ve erkek konuşmacıya dayalı formant değerleri 


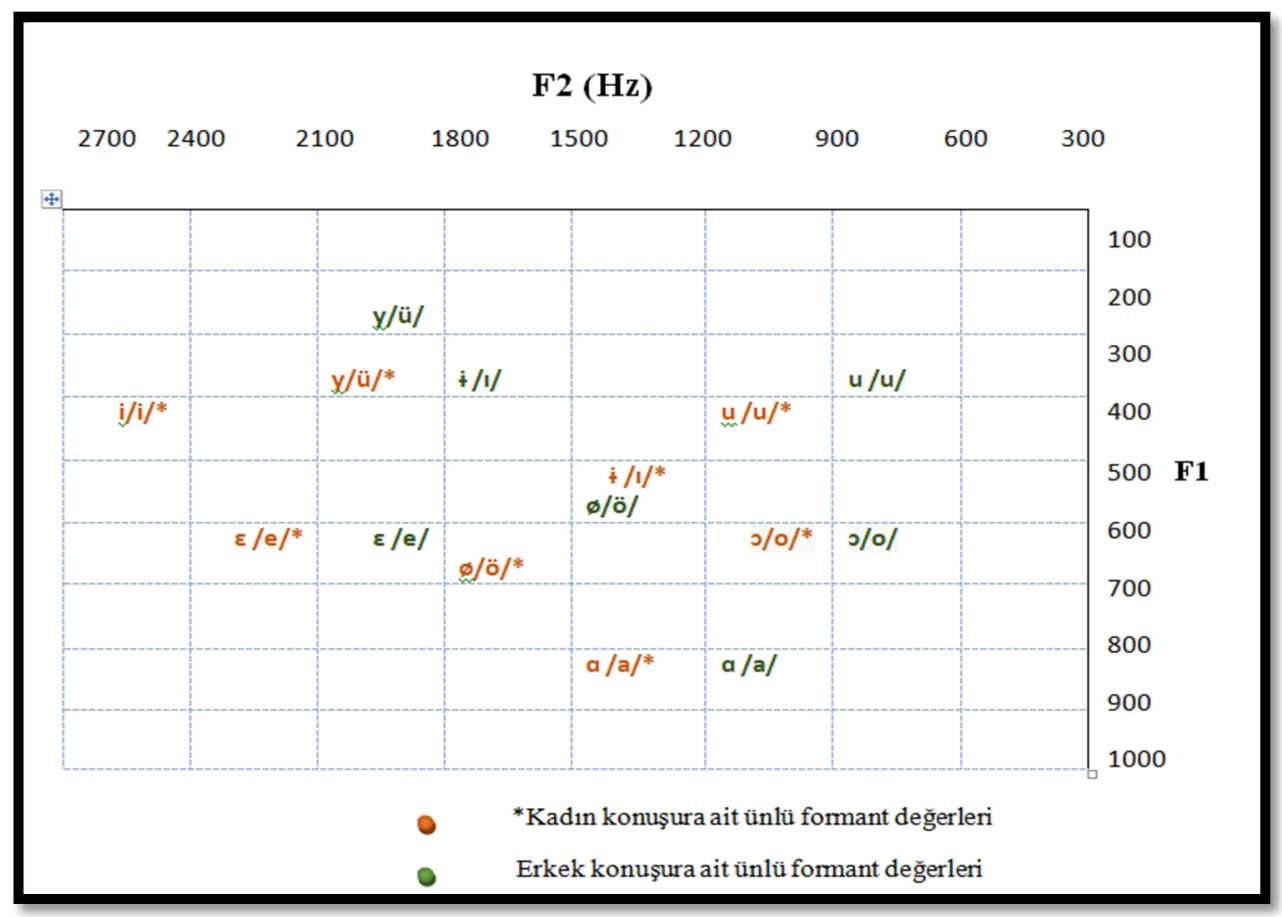

Şekil 10. Ünlülerin kadın ve erkek konuşura ait formant dağılımları

Uluslar arası Sesbilgisi Alfabesi (IPA)'nde ünlülerin belirlenen formant değerleri tek erkek konuşucuya aittir-Türkçede belirlenen formant değerlerini karşılaştırmak bakımından- ve şu tabloda belirtilmiştir (Catford, 1988:161).

\begin{tabular}{|c|c|c|}
\hline $\begin{array}{l}\text { Vowel } \\
\text { (IPA) }\end{array}=$ & $\begin{array}{l}\text { First Formant frequency } \\
\qquad \begin{array}{l}\left(f_{1}\right. \\
(\mathrm{Hz}))\end{array}\end{array}$ & $\begin{array}{l}\text { Second Formant frequency } \\
\qquad \begin{array}{c}\left(f_{2}\right. \\
(H z))\end{array}\end{array}$ \\
\hline i & 240 & 2400 \\
\hline$y$ & 235 & 2100 \\
\hline $\mathrm{e}$ & 390 & 2300 \\
\hline$\varnothing$ & 370 & 1900 \\
\hline$\varepsilon$ & 610 & 1900 \\
\hline$œ$ & 585 & 1710 \\
\hline a & 850 & 1610 \\
\hline$C E$ & 820 & 1530 \\
\hline$a$ & 750 & 940 \\
\hline D & 700 & 760 \\
\hline$\wedge$ & 600 & 1170 \\
\hline 0 & 500 & 700 \\
\hline$\gamma$ & 460 & 1310 \\
\hline 0 & 360 & 640 \\
\hline$w$ & 300 & 1390 \\
\hline $\mathbf{u}$ & 250 & 595 \\
\hline
\end{tabular}

Tablo 6. Bir erkek konuşurdan elde edilen IPA formant değerleri 
WALS’e göre diller arasındaki karşılaştırmalı tablolara göre Türkçe ünlü bakımdan iki grupta büyük kategorisindedir. Bunlar 564 dil içerisinde yapılan değerlendirmeler sonucu elde edilen verilerdir. Çalışmayla ilgisi bakımından bu iki başlık ünlü sayıları ve ön-yuvarlak ünlülerin bulunmasıyla ilgili başlıklardır. Buna göre ünlü sayıları bakımından Türkçe büyük kategorisinde yer almaktadır (Maddieson, 2013b):

\begin{tabular}{|l|l|}
\hline Değer & Gösterim \\
\hline Küçük (2-4 ünlü) & 93 \\
\hline Ortalama (5-6 ünlü) & 287 \\
\hline Büyük (7-14 ünlü) & 184 \\
\hline Toplam dil & 564 \\
\hline
\end{tabular}

Tablo 7. WALS’e göre ünlü sayıları bakımından diller

Ön-yuvarlak ünlülere sahip olma bakımından da Türkçe 562 dil içinde dar ve yarı-dar ön yuvarlak ünlülere sahip diller arasında bulunmaktadır (Maddieson, 2013h):

\begin{tabular}{|l|l|}
\hline Değer & Gösterim \\
\hline Ön yuvarlak ünlüsü olmayan & 525 \\
\hline Dar -yarı dar ön yuvarlak ünlüsü bulunan & 23 \\
\hline Yalnızca dar ön yuvarlak ünlüsü bulunan & 8 \\
\hline Yalnızca yarı dar orta ön yuvarlak ünlüsü bulunan & 6 \\
\hline
\end{tabular}

Tablo 8. WALS’e göre ön-yuvarlak ünlüler bakımından diller

\section{Sonuç}

7. yüzyıldan günümüze sözcük ahengini oluşturan ünlülerin oluşumu ile ilgili birçok görüş ortaya atılmıştır. Bunların kırılma noktası ise D. Jones'un "Kardinal Ünlü Kuramı"dır. Jones kendisinden sonra gelen ve birçoğu öğrencisi olan sesbilimcileri de bu Kuram’ı konusunda yetiştirerek farklı ve daha gelişmiş kuramların ortaya çıkmasını sağlamıştır. Genel olarak tüm bu kuramlar, ünlülerin diller arasındaki seçiminin nedenini bulmak üzerine fikirler sunmaktadır. Bazı kuramlarda bu neden eklemleme kolaylığına bağlanırken bazı kuramlarda ise dinleyicinin algısal seçiciliği gerekçe gösterilmektedir. Genel yargı ise ağız içerisinde en önde üretilen [i] ile en arkada üretilen [a] ünlülerinin temel ünlüler olduğu yönündedir. Bu ünlüler ile birlikte dudak oluşumu esasılyla [u] ünlüsü de formant değeri bakımından üçüncü asıl ünlü olarak kabul edilir. Geri kalan tüm ünlüler sesbilimsel ve sesbilgisel olarak bu ünlülerin üretim noktaları çevresinde oluşmaktadır. Bu genel kabul önce bir sezgi ile ardından teknolojik ses çözümlemelerinin verileriyle bilimsel bir gerçekliğe dönüşmüştür.

Bu bağlamda Türkçe de bu asıl ünlülere sahip birçok dil gibidir. Bununla birlikte Türkçede temel ünlü sayısı fazladır. Bu ünlülerin dağılımı da bu kuramlar çerçevesinde ana üç ünlüye göre yapıldığında Türkçenin ünlülerinin üçgenden öte dörtgen oluşturduğu görülür. Bu durumu sağlayan da Türkçede ön ve arka yuvarlak ünlülerin bulunmasıdır. Çalışmada erkek ve kadına ait sesler laboratuvar ortamında eşit ses hızıyla kaydedilmiştir. Ünlülere ait bu sesler PRAAT ses çözümleme programında F1 ve F2 değerleri gözetilerek çözümlenmiştir. Yapılacak çalışmalarda sözcük içi ünlü gösterimleri için 
F3 değeri de gösterildiğinde ölçümlerin karşılaştırması sesbilgisel olarak daha ayrıntılı olabilecektir. Burada amaç tek başına ünlülerin sesletimindeki formant ölçümlerini belirlemektir.

Bundan sonra yapılacak çalışmalarda ünlü nitelikleri, çevre sesler etkisiyle birçok konuşmacıdan alınacak kayıtlarla tek ve çok heceli sözcüklerin sesletimini kapsamalıdır. Bu çalışmada yalın olarak verilen ünlü çözümlemeleri, çevre seslerin etkisiyle şekillenmiş ünlü değerlerinin çözümlenmesiyle zenginleşerek sesbilimsel (fonolojik) bilginin sesbilgisel (fonetik) çıtısı olarak alan yazına kazandırılmalıdır.

\section{Kaynakça}

Bell, A. M. (1867). Visible Speech. London, Methuen

Catford, J.C. (1988). A Practical Introduction to Phonetics. Oxford University Press.

Flemming E. (1996). Evidence for constraints on contrast: The dispersion theory of contrast. Hsu, Chai Shune (ed.) UCLA Working Papers in Phonology 1.

Flemming E. (1997). Phonetic Optimization: Compromise in Speech Production, University of Maryland Working Papers in Linguistics 5: Selected phonology papers from H-OT-97.

Flemming E. (2001). Scalar and categorical phenomena in a unified model of phonetics and phonology. Phonology 18(1).

Flemming E. (2011). The grammar of coarticulation (English draft). In M. Embarki and C. Dodane (eds.) La Coarticulation: Indices, Direction et Representation.

Jones, D. (1956). Cardinal Vowels, Linguaphone Institute, London.

Jones, D. (1972). An Outline of English Phonetics (9th ed.). Cambridge: W. Heffer \& Sons Ltd

Stevens, K.N. (1972). The quantal nature of speech: Evidence from articulatory-acoustic data. In Denes, P.B. and David Jr., E.E. (eds.), Human Communication, A Unified View, 51-66. New York, McGraw-Hill.

Ladefoged, P. (1967). Three areas of experimental phonetics. London: Oxford Unv. Press

Liljencrantz, J., \& Lindblom, B. (1972). Numerical Simulation of Vowel Quality Systems, The Role of Perceptual Contrast. Language, 48, 839-862.

Maddieson I., (2013b). Vowel quality inventories. M.S. Dryer and M. Haspelmath (Haz.), The World atlas of Language Structures Online içinde. Almanya: MAx-Planck-Institut für evolutionare Anthropologie.

Maddieson I., (2013h). Front rounded vowels. M.S. Dryer and M. Haspelmath (Haz.), The World atlas of Language Structures Online içinde. Almanya: MAx-Planck-Institut für evolutionare Anthropologie.

Peterson, G. E., ve Barney, H.L. (1952). Control Methods Used in a Study of the Vowels. Journal of the Acoustical Society of America, 24, 175-184

Stevens, K.N. ; Keyser, S.J. and Kawasaki, H. (1986). Toward a Phonetic and Phonological Theory of Redundant Features, in Invariance and Variability in Speech Processes, Lawrence Erlbaum Associates, pp. 426-463. Lawrence Erlbaum Associates.

Stevens, K.N. (1989). On the quantal nature of speech. Journal of Phonetics 17, 3-46.

Taylan, Erguvanll, E. (2015). The Phonology And Morphology Of Turkish. İstanbul: Boğaziçi ünv. Yay.

\section{Açık Erişim Kaynakları}

extension://ohfgljdgelakfkefopgklcohadegdpjf/https://web.stanford.edu/class/linguist205/index_file s/Handout\%208\%20-\%20QT\%20\&\%20Adaptive\%20Dispersion.pdf

https://player.slideplayer.com/12/3511685/\# 
252 / RumeliDE Journal of Language and Literature Studies 2020.S7 (October)

Vowels in Turkish within the framework of theories related to vowels / G. Erdem Nas (pp. 237-252)

https://wals.info/

Adres | Address

Kırklareli Üniversitesi, Fen Edebiyat Fakültesi, Türk Dili ve Edebiyatı Kırklareli University, Faculty of Arts and Sciences, Department of Bölümü, Kayalı Kampüsü-Kırklareli/TÜRKIYE $\quad$ Turkish Language and Literature, Kayalı Campus-Kırklareli/TURKEY e-posta: editor@rumelide.com 1 e-mail: editor@rumelide.com 